\title{
A APLICAÇÃO DO PMBOK® NA GESTÃO DE PROJETOS EM UNIDADES DE INFORMAÇÃO
}

\author{
A APLICAÇÃO DO PMBOK® NA GESTIÓN DE \\ PROYECTOS EM UNIDADES DE INFORMAÇÃO
}

\author{
Daniela Spudeit* \\ Helio Aisenberg Ferenhof**
}

\begin{abstract}
RESUMO:
Introdução: As unidades de informação devem ser cada vez mais vistas como organizações prestadoras de serviços cujo principal insumo é a informação que agrega valor às instituições e formação do capital intelectual. Esse contexto aponta uma necessidade de planejamento para atendimento das necessidades informacionais dos seus clientes. Objetivo: O objetivo deste estudo é apresentar a gestão de projetos como uma das alternativas para promover a eficácia no planejamento e execução em uma unidade de informação por meio de soluções que atendam estas necessidades. Metodologia: Um estudo bibliográfico e exploratório foi conduzido em busca reforçar que o uso das melhores práticas de gerenciamento de projetos pode ajudar muito a gestão de unidades de informação. Resultados: Como resultados obtidos, aponta-se que todas as dez áreas do PMBOK® são aplicáveis em unidades de informação e, cabe ao bibliotecário, promover a execução, acompanhamento e finalização desses processos. Conclusão: As unidades de informação têm como missão promover o acesso as fontes de informação e por isso é importante que sejam adotadas as boas práticas do $\mathrm{PMBOK} \circledast$ pois aceleram o lançamento de produtos e serviços, reduzem custos, melhoram os controles de qualidade e otimizam recursos e esforços.
\end{abstract}

Palavras-chave: Gestão de projetos. PMBOK. Unidades de informação. Biblioteconomia. Bibliotecas.

\section{INTRODUÇÃO}

No vídeo "De onde vem as ideias" de Steven Johnson, escritor norte americano pesquisador da Universidade de Columbia, apresenta um contexto social em que as ideias surgem e como elas se formam por meio de trocas, *Mestre em Ciência da Informação pela Universidade Federal de Santa Catarina (UFSC). Docente em Biblioteconomia e Pós-Graduação de Gestão da Informação da Universidade do Estado de Santa Catarina (UDESC). E-mail: danielaspudeit@gmail.com ${ }^{* *}$ Doutor em Engenharia de Produção - PPGEP - UFSC. E-mail: dm@gotroot.com.br 
experiências, compartilhamentos e criatividade. As ideias também são influenciadas pelas tecnologias, pelo tempo, pelas pessoas, por recursos, entre outros elementos para serem transformadas e sistematizadas em forma de projetos para que se transformem em ações efetivas para melhoria de um processo ou captação de um recurso.

Torna-se cada vez mais importante a elaboração de projetos pelos gestores como instrumento de sistematização das ideias em ações efetivas devido à competitividade constante e fluída em que as pessoas e tecnologias são afetadas pelo fluxo informacional que moldam as organizações e ditam as mudanças sociais, políticas e econômicas.

Projeto pode ser definido como sendo um esforço temporário afim de desenvolver um produto, seja um bem ou serviço exclusivo (PMBOK, 2013). Corroborando com este conceito, Almeida (2005, p. 93) conceitua projeto como "a unidade elementar do processo de planejamento constituindo-se em um conjunto de ações e recursos para a consecução de objetivos concretos", ou seja, são instrumentos importantes para geração de benefícios. Maximiano (2002, p. 20) concorda citando que "são empreendimentos finitos com objetivos definidos em função de um problema, oportunidade ou interesse da organização". Vargas (2005, p.7) une as definições de Almeida (2005) e Maximiano (2005), enfatizando que:

Os projetos são atividades caracterizadas por uma sequência clara e lógica de eventos para atingir objetivos dentro de um tempo, custo e recursos prévios definidos, combinam recursos organizacionais e necessitam de uma coordenação para controle de prazos, custos e desempenho pois atingem todos os níveis de uma organização e as partes interessadas externas à instituição assim como os clientes, fornecedores, parceiros, governo, etc.

Frente às demandas existentes em um ambiente atual competitivo caracterizado pela valorização do capital intelectual, trabalho colaborativo, inteligência competitiva e gestão do conhecimento, torna-se indispensável que as organizações desenvolvam um modelo de gestão de projetos com foco em prioridades e objetivos estabelecidos bem claros com base em um processo estruturado e lógico para lidar com eventos que se caracterizam por essa dinâmica ambiental. 
Esta nova dinâmica organizacional exige profissionais mais qualificados, rápidos, eficientes que busquem constantemente resultados eficazes com cada vez menos recursos, menos tempo e mais qualidade exigida pelas organizações.

A tendência é que a competição continue pressionando para que as melhores ideias se processem e sejam implantadas em curto prazo. É nesse limiar que o planejamento contribui para o processo que se origina a partir da elaboração de projetos. Estes precisam ser gerenciados para obter melhores resultados, inclusive em unidades de informação em que o bibliotecário lida com diferentes suportes informacionais com demandas e perfis de clientes diferenciados.

As unidades de informação devem ser cada vez mais vistas como organizações prestadoras de serviços, cujo principal insumo é a informação que agrega valor às instituições e formação do capital intelectual. Dessa forma, é preciso que haja uma preocupação de planejamento e gestão de projetos para atendimento das necessidades informacionais dos clientes que buscam os serviços oferecidos pelas unidades de informação para atendimento eficaz dessa demanda. Planejar um projeto é tomar decisões que permitam implementá-lo. Sem planejamento, não se pode iniciar um projeto, acompanhar seu desenvolvimento e avaliar seus resultados.

Desta forma, por meio de um estudo bibliográfico, descritivo e exploratório, este trabalho apresenta os principais autores da área de gestão de projetos e articula os conceitos abordados nas melhores práticas descritas no PMBOK® para apropriação e aplicação no desenvolvimento de projetos em unidades de informação pelos bibliotecários a fim de facilitar a gestão.

\section{GESTÃO DE PROJETOS}

A gestão de projetos é um conjunto de ferramentas gerenciais que permite que a empresa desenvolva um conjunto de habilidades, incluindo conhecimento e capacidades individuais, destinado ao controle de eventos não repetitivos, únicos e complexos, dentro de um cenário de tempo custo e 
qualidade pré-determinados (VARGAS, 2005; PMBOK, 2013). Deste modo, Vargas (2005, p. 7) explica que gestão de projetos:

São atividades caracterizadas por uma sequência clara e lógica de eventos para atingir objetivos dentro de um tempo, custo e recursos prévios definidos, combinam recursos organizacionais e necessitam de uma coordenação para controle de prazos, custos e desempenho pois atingem todos os níveis de uma organização e as partes interessadas externas à instituição assim como os clientes, fornecedores, parceiros, governo, etc.

Para efetuar a gestão é preciso planejamento, no caso de um projeto envolve a tomada de decisões que permitam implementar as ideias do projeto. Sem planejamento, não se pode iniciar um projeto, acompanhar seu desenvolvimento e avaliar seus resultados.

Dessa forma, é importante que o projeto seja dividido em fases que definam, meçam, analisem, melhorem e controlem as etapas do projeto ara obter o resultado esperado. Almeida (2005) cita quais são essas etapas: Definição do objeto e objetivos, planejamento das ações e atividades, planejamento da capacitação da equipe de implementação, planejamento da avaliação, planejamento de recursos, planejamento das estratégias de disseminação e comunicação. Essas etapas fazem parte de um ciclo, denominado ciclo de vida do projeto, onde todo projeto pode ser subdividido em fases de desenvolvimento que englobam a fase de iniciação, fase de planejamento, fase de execução, monitoramento e controle e por fim, a fase de encerramento (MAXIMIANO, 2002; VARGAS, 2005, PMBOK, 2013) conforme a seguir.

Figura 1 - Ciclo de vida de um projeto

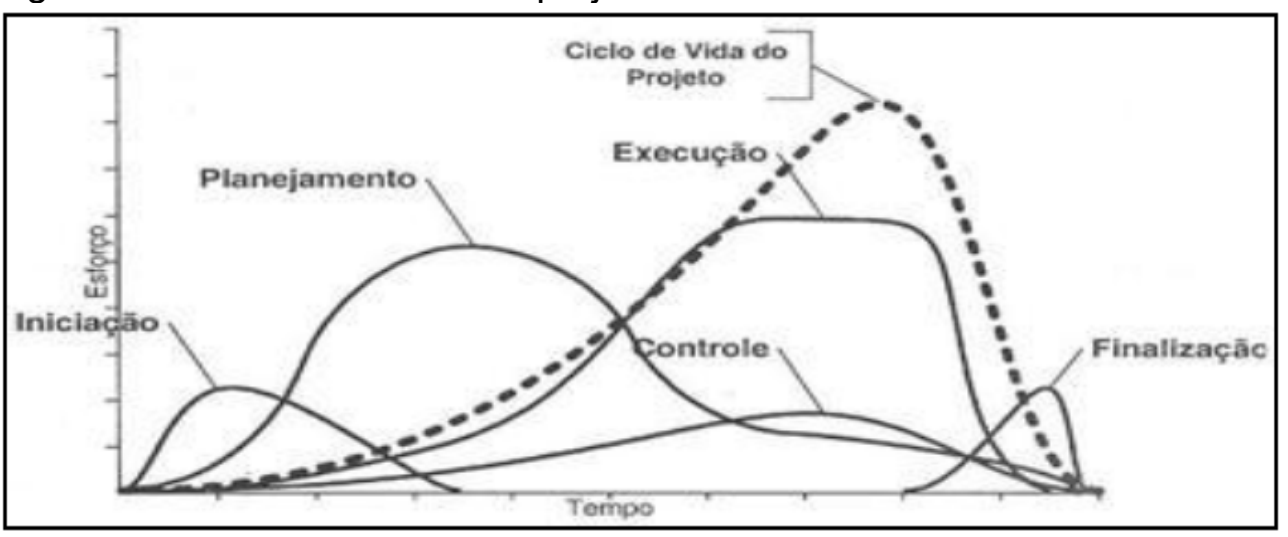

Fonte: Vargas (2005, p. 35)

Inf. Inf., Londrina, v. 22, n. 1, p. 306 - 330, jan./abr., 2017. http:www.uel.br/revistas/informacao/ 
São consideradas cinco fases características de um projeto definidas por Vargas (2005, p. 39):

- $\quad$ Fase de definição: é a fase inicial do projeto. Nela, a missão e o objetivo do projeto são definidos.

- $\quad$ Fase de planejamento: é responsável por identificar e selecionar as melhores estratégias de abordagem do projeto, detalhando tudo aquilo que será realizado.

- $\quad$ Fase de execução: é quando se materializa tudo aquilo que foi planejado anteriormente. Qualquer erro cometido nas fases anteriores fica evidente durante essa etapa. Grande parte do orçamento e do esforço do projeto é consumida aqui.

- Fase de controle: é a que acontece paralelamente ao planejamento operacional e à execução do projeto. Tem como objetivo acompanhar e controlar aquilo que está sendo realizado pelo projeto de modo a propor ações corretivas e preventivas no mínimo espaço de tempo possível após a detecção da anormalidade.

- $\quad$ Fase de finalização: é quando a execução dos trabalhos é avaliada por auditoria interna ou externa (terceiros).

As fases permitem ajustes, monitoramento e controle dos recursos para atingir metas estabelecidas. As fases são divididas em estágios ou etapas que são subdivididas em atividades ou tarefas conforme Figura 2. Cada fase tem características próprias, com necessidades de informação e aprendizagem diferenciadas das atividades rotineiras da organização (MONTEIRO; VALENTIM, 2008).

Figura 2 - Fases de um projeto

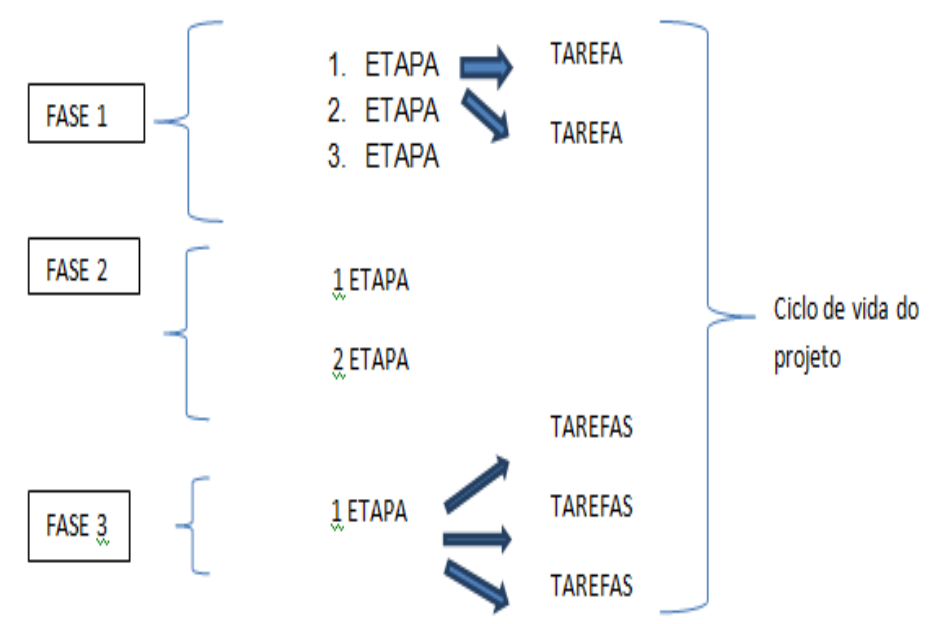

Fonte: Vargas (2005)

Inf. Inf., Londrina, v. 22, n. 1, p. 306 - 330, jan./abr., 2017. http:www.uel.br/revistas/informacao/ 
Cada fase do projeto normalmente define qual trabalho técnico deve ser realizado e quem deve estar envolvido. Percebe-se que a principal vantagem do gerenciamento de projetos é que ele não é restrito a grandes projetos e pode ser aplicado a qualquer empreendimento pois evita problemas ao longo da execução dos trabalhos, anteveem situações de conflitos ou de falta de recursos permitindo ações preventivas, desenvolve diferenciais competitivos, agiliza a tomada de decisão, otimiza a locação de pessoas, entre outras vantagens (PMBOK, 2013).

Mesmo assim podem acontecer falhas nos projetos causados por fatores externos, internos e ambientais impactados pela tecnologia, política, custos, economia, etc. Deste modo, para pensar em diretrizes que pudessem auxiliar no desenvolvimento dos projetos e aplicação de conhecimentos, habilidades, ferramentas e técnicas às atividades do projeto para atender aos seus requisitos, um grupo de gestores de projetos se uniu e começou a compartilhar informações pertinentes ao sucesso e fracasso na gestão de projetos, surgindo assim o Project Management Institute (PMI) e a primeira versão do Guia de Melhores Práticas de Gerenciamento de Projetos (Project Management Body of Knowledge - PMBOK®).

Atualmente, o guia de melhores práticas $\mathrm{PMBOK} \circledast$ é a principal fonte de informação utilizada para embasar o gerenciamento de projetos no mundo, desenvolvido pelo PMI, uma das maiores associações de e para profissionais em gerenciamento de projetos. O trabalho deste instituto é auxiliar e evoluir a área de gestão de projetos bem como os profissionais em suas carreiras e tornando assim a profissão mais consolidada.

De acordo com o PMI, o Guia é composto pelas melhores práticas de gestão de projetos, isto significa que o conhecimento e as práticas descritas são aplicáveis a maioria dos projetos na maior parte do tempo e que existe um consenso em relação ao seu valor e sua utilidade. Ainda de acordo com este guia, uma boa prática corresponde a aplicação correta das habilidades, ferramentas e técnicas já testadas amplamente por um grande grupo de gestores de projetos que pode aumentar as chances de sucesso em uma ampla gama de projetos (PMBOK, 2013). 
Destaca-se que uma boa prática não significa que todas as áreas de conhecimento expostas devam ser sempre utilizadas uniformemente em todos os projetos. Deve-se levar em conta o tipo de projeto, tamanho, tempo destinado. Fatores organizacionais e ambientais. Cabe ao gestor de projetos, bem como sua equipe e a empresa em que trabalha determinar o que é apropriado para um projeto específico (PMBOK, 2013).

De acordo com o PMBOK, o gerenciamento de projetos é desempenhado por meio da aplicação e integração apropriadas de 47 processos, agrupados em 10 áreas de conhecimento distintas conforme figura 3.

Figura 3 - Áreas do conhecimento do PMBOK

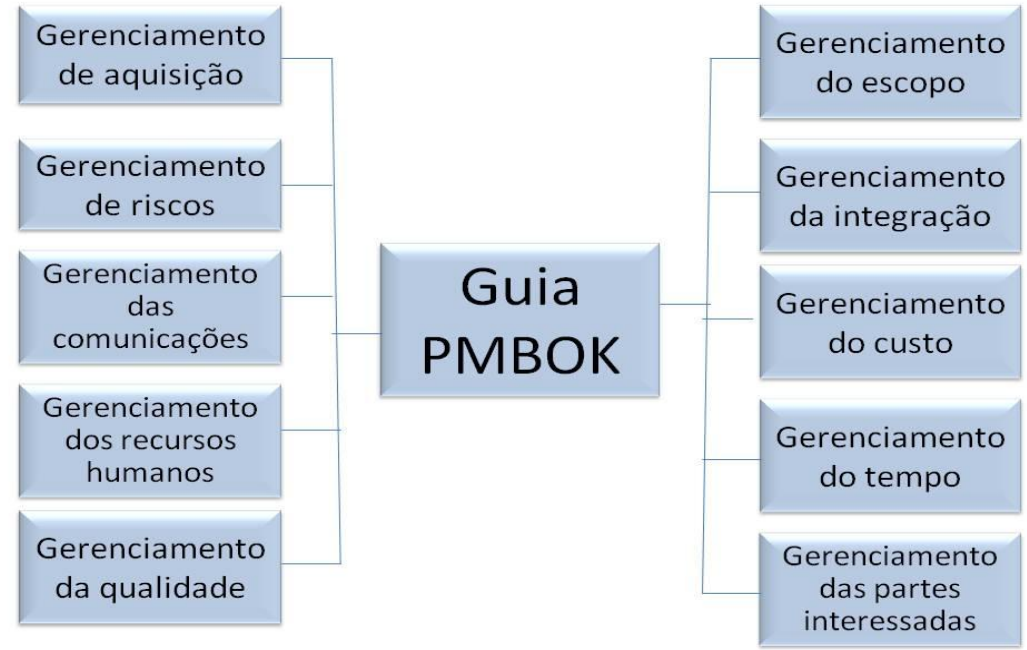

Fonte: PMI (2013)

Destaca-se que para o guia PMBOK (2013), uma área de conhecimento significa uma área de especialização, ou seja, um conjunto completo de constructos, termos, conceitos, e atividades que compõem uma área profissional. As áreas de conhecimento são:

1. Gerenciamento de integração do projeto: responsável pela abertura, encerramento e gestão das demais áreas;

2. Gerenciamento do escopo do projeto: responsável por definir todo o trabalho a ser feito pelo projeto nada a mais e nada a menos;

3. Gerenciamento do tempo do projeto: responsável por decompor as entregas em atividades e atribuir um tempo a elas, resultando em um cronograma a ser seguido; 
4. Gerenciamento do custo do projeto: responsável por definir, acompanhar e controlar os custos incorridos no projeto;

5. Gerenciamento da qualidade do projeto: responsável por especificar o nível de aceitação e garantir que este seja atingido ao longo de todo projeto;

6. Gerenciamento dos recursos humanos do projeto: responsável por identificar, alocar, e prover o crescimento dos indivíduos alocados nos projetos;

7. Gerenciamento das comunicações do projeto: responsável por identificar, criar e controlar as formas e canais de comunicação sejam internos ou externos ao projeto;

8. Gerenciamento dos riscos do projeto: responsável pela identificação e análise das oportunidades e ameaças que possam incorrer a pelo menos um dos objetivos do projeto;

9. Gerenciamento de aquisições do projeto: responsável por planejar, executar e gerir as compras, alugueis, terceirização de recursos sejam bens materiais, pessoal terceirizado;

10. Gerenciamento das partes interessadas no projeto: responsável por identificar, analisar e gerenciar as influências, sejam positivas ou negativas, destes em pelo menos um dos objetivos do projeto.

As dez áreas de conhecimento são logicamente agrupadas em cinco grupos de processos: Iniciação; Planejamento; Execução; Monitoramento e controle e; Encerramento. Este agrupamento foi criado com intuito de aclarar o entendimento da inter-relação dos processos e as fases no qual ocorrem, representadas pela figura 4. 
Daniela Spudeit, Helio Aisenberg Ferenhof.

A aplicação do PMBOK® na gestão de projetos em unidades de informação

Figura 4 - Guia do PMBOK®

\begin{tabular}{|c|c|c|c|c|c|}
\hline \multicolumn{6}{|c|}{ Guia PMBOK 5a Edição } \\
\hline \multirow[t]{2}{*}{ Áreas do Conhecimento } & \multicolumn{5}{|c|}{ Grupos de Processos } \\
\hline & Iniciação & Planejamento & Execução & Monitoramento e Controle & Encerramento \\
\hline \multirow{2}{*}{ Integraçāo } & $\begin{array}{l}\text { 4.1 Desenwolver Termo de } \\
\text { Abertura do Projeto }\end{array}$ & $\begin{array}{l}4.2 \text { Desenvolver Plano de } \\
\text { Gerenciamento do Projeto }\end{array}$ & $\begin{array}{l}4.3 \text { Orientar e Gerenciar a } \\
\text { Execuçăo do Projeto }\end{array}$ & $\begin{array}{l}4.4 \text { Monitorar e Controlar o } \\
\text { Trabalho do Projeto }\end{array}$ & $\begin{array}{l}4.6 \text { Encerrar Projeto ou } \\
\text { Fase }\end{array}$ \\
\hline & & & & $\begin{array}{l}\text { 4.5 Realizar Controle integrado de } \\
\text { Mudanças }\end{array}$ & \\
\hline \multirow{4}{*}{ Escopo } & & $\begin{array}{l}5.1 \text { Planejaf } \\
\text { Gerenciamento do Escopo }\end{array}$ & & 5.5 Validar Escopo & \\
\hline & & 5.2 Coletar Requisitos & & 5.6 Controlar Escopo & \\
\hline & & 5.3 Definir Escopo & & 6.7 Controlar Cronograma & \\
\hline & & 5.4 Criar EAP & & & \\
\hline \multirow{6}{*}{ Tempo } & & $\begin{array}{l}6.1 \text { Planejar } \\
\text { Gerenciamento de Tempo }\end{array}$ & & & \\
\hline & & 6.2 Definit Atividades & & & \\
\hline & & 6.3 Sequenciar Atividades & & & \\
\hline & & $\begin{array}{l}6.4 \text { Estimar Recursos das } \\
\text { Atividades }\end{array}$ & & & \\
\hline & & $\begin{array}{l}6.5 \text { Estimar Duraçōes das } \\
\text { Atividades }\end{array}$ & & & \\
\hline & & $\begin{array}{l}\text { 6.6 Desenvolver } \\
\text { Cronograma }\end{array}$ & & & \\
\hline \multirow{3}{*}{ Custo } & & $\begin{array}{l}\text { 7.1 Planejar } \\
\text { Gerenciamento de Custo }\end{array}$ & & 7.4 Controlar Custos & \\
\hline & & 7.2 Estimar Custos & & & \\
\hline & & 7.3 Criar Orçamento & & & \\
\hline Qualidade & & $\begin{array}{l}\text { 8.1 Planejar } \\
\text { Gerenciamento da } \\
\text { Qualidade }\end{array}$ & $\begin{array}{l}\text { 8.2 Realizar Garantia da } \\
\text { Qualidade }\end{array}$ & 8.3 Realizat Controle da Qualidade & \\
\hline \multirow{3}{*}{ Recursos Humanos } & & $\begin{array}{l}\text { 9.1 Planejar } \\
\text { Gerenciamento dos } \\
\text { Recursos Humanos }\end{array}$ & $\begin{array}{l}\text { 9.2Mobilizar Equipe do } \\
\text { Projeto }\end{array}$ & & \\
\hline & & & $\begin{array}{l}\text { 9.3 Desenwolver Equipe do } \\
\text { Projeto }\end{array}$ & & \\
\hline & & & $\begin{array}{l}9.4 \text { Gerenciar Equipe do } \\
\text { Projeto }\end{array}$ & & \\
\hline Comunicação & & $\begin{array}{l}10.1 \text { Planejar } \\
\text { Gerenciamento da } \\
\text { Comunicaçäo } \\
\end{array}$ & $\begin{array}{l}10.2 \text { Getenciar } \\
\text { Comunicaçăo }\end{array}$ & 10.3 Controlar Comunica,30 & \\
\hline \multirow{5}{*}{ Riscos } & & $\begin{array}{l}11.1 \text { Planejar } \\
\text { Gerenciamento de Riscos }\end{array}$ & & 11.6 Monitorar e Controlar Riscos & \\
\hline & & 11.2 Identificar Riscos & & & \\
\hline & & $\begin{array}{l}\text { 11.3 Realizar Análise } \\
\text { Qualitativa dos Riscos }\end{array}$ & & & \\
\hline & & $\begin{array}{l}11.4 \text { Realizar Análise } \\
\text { Quantitativa dos Riscos }\end{array}$ & & & \\
\hline & & $\begin{array}{l}11.5 \text { Planejar Respostas aos } \\
\text { Riscos }\end{array}$ & & & \\
\hline Aquisiçōes & & $\begin{array}{l}12.1 \text { Planejar } \\
\text { Gerenciamento das } \\
\text { Aquisiçōes } \\
\end{array}$ & 12.2 Conduzit Aquisiç̋̄es & 12.3 Administrar Aquisiç̧̋̄es & 12.4 Encerfar Aquisiçbెes \\
\hline Partes Interessadas & $\begin{array}{l}13.1 \text { identificar Partes } \\
\text { interessadas }\end{array}$ & $\begin{array}{l}\text { 13.2 Planejar } \\
\text { Gerenciamento das Partes } \\
\text { Interessadas }\end{array}$ & $\begin{array}{l}13.3 \text { Gerenciar Partes } \\
\text { Interessadas }\end{array}$ & $\begin{array}{l}13.4 \text { Monitorar Gerenciamento das } \\
\text { Partes Interessadas }\end{array}$ & \\
\hline
\end{tabular}

Fonte: PMBOK (2013).

\section{PROCEDIMENTOS METODOLÓGICOS}

Trata-se de uma pesquisa bibliográfica, descritiva e exploratória que objetiva gerar conhecimentos novos para avanço da ciência com intuito de apresentar uma proposta de aplicação das diretrizes do PMBOK® no gerenciamento de projetos em unidades de informação.

Inf. Inf., Londrina, v. 22, n. 1, p. 306 - 330, jan./abr., 2017. http:www.uel.br/revistas/informacao/ 
É uma pesquisa bibliográfica, porque consiste em coletar material publicado sobre o objeto da pesquisa em questão. De acordo com Martins e Theóphilo (2009, p. 54) "uma pesquisa bibliográfica procura explicar e discutir um assunto, tema ou problema com base em referências publicadas. Busca conhecer, analisar e explicar contribuições sobre determinado assunto, tema ou problema".

Neste caso, foi feito o levantamento bibliográfico sobre gestão de projetos em unidades de informação e também sobre o uso do Guia PMBOK®. Os levantamentos são próprios em pesquisas que investigam questões da maneira como ocorrem em situações naturais sem necessidade de controlar variáveis e simplificar fenômenos indo além do relato de distribuições e relações, mas também buscam realizar a sua explicação e interpretação (MARTINS; THEÓPHILO, 2009).

Sob o ponto de vista do objetivo, trata-se de um estudo exploratório e descritivo. As pesquisas exploratórias visam "proporcionar maior familiaridade com o problema, com vistas a torná-lo mais explícito ou a construir hipóteses. Pode-se dizer que estas pesquisas têm como objetivo principal o aprimoramento de ideias ou a descoberta de intuições." (GIL, 2010, p 45). Como pesquisa descritiva o mesmo autor define que elas "têm como objetivo primordial a descrição das características de determinada população ou fenômeno ou, então, o estabelecimento de relações entre variáveis". (op. cit. : 46).

Para a coleta de dados, foi feita uma pesquisa nos campos título, resumo e palavras-chave sobre os termos "gestão de projetos", "bibliotecas", "unidades de informação" nos principais repositórios e bases de dados nacionais e internacionais de acesso aberto na Ciência da Informação tais como BRAPCI, RABCI, SCIELO e E-LIS.

O E-prints de Biblioteconomia e Ciência da Informação (E-LIS) e o Scientific Electronic Library Online (SCIELO) são repositórios de acesso público internacional disponível em acesso aberto formado por documentos digitais resultante da cooperação entre instituições de pesquisa. Os repositórios abertos brasileiros Bases de Dados Referenciais de Artigos de Periódicos em Ciência da Informação (BRAPCI) e Repositório acadêmico de Biblioteconomia 
e Ciência da Informação (RABCl) são indexados periódicos e trabalhos acadêmicos da área de Ciência da Informação e Biblioteconomia tendo como objetivo ser um espaço de compartilhamento de trabalhos e ideias da área.

\section{GESTÃO DE PROJETOS COM APLICAÇÃO DAS MELHORES PRÁTICAS DO PMBOK® EM UNIDADES DE INFORMAÇÃO}

A gestão de projetos não é comum ocorrer em bibliotecas e muito menos encontrar relatos sobre gerenciamento de projetos em unidades de informação com base nas melhores práticas do guia PMBOK®.

Após o levantamento bibliográfico, foram encontrados apenas três estudos publicados que descrevem essa dimensão gerencial dentro da Ciência da Informação conforme apresentados a seguir por Monteiro e Falsarella (2007), Brusamolin e Moresi (2008) e Monteiro e Valentim (2008), porém, nada remete a aplicação do PMBOK em unidades de informação.

\subsection{Estudos sobre gestão de projetos na Ciência da Informação}

Monteiro e Falsarella (2007) apresentam um modelo de gestão da informação de modo a se obter aprendizagem organizacional por meio de projetos. Os autores relacionam a interface existente entre a área da Administração ligada a gestão de projetos e a Ciência da Informação mostrando que os projetos são grandes consumidores e produtores de informação com intenso fluxo que precisa bem administrado para beneficiar a execução do projeto. Os autores explicam que "vários são os sistemas de informação usados em projetos, entre eles tem o Sistema de Informações Gerenciais (SIG) - que tem como função o apoio às atividades funcionais e aos administradores" (MONTEIRO; FALSARELLA, 2007, p. 87).

Neste contexto, sugerem que haja essa preocupação por parte dos gestores com os processos de busca, produção, tratamento, armazenamento e disseminação da informação para que a informação flua entre a equipe e gere um aprendizado organizacional no decorrer do desenvolvimento do projeto.

A pesquisa de Brusamolin e Moresi (2008) relata o emprego de narrativas de histórias para compartilhar experiências e promover a gestão do 
conhecimento num ambiente colaborativo. Para isso, apresentam uma proposta de emprego de narrativas de histórias para facilitar o gerenciamento de projetos. Os autores alertam para a ausência de trabalhos e pesquisas sobre essa temática após terem feito uma revisão de literatura nas bases Scopus $₫$ e Web of Science $®$.

Por meio de uma pesquisa quanti-qualitativa, os autores mostram que a narrativa de histórias consiste em uma técnica de gestão do conhecimento aplicável no gerenciamento de projetos de tecnologia da informação, contribuindo com o gerenciamento de projetos à medida que facilita a comunicação entre as pessoas. De acordo com Brusamolin e Moresi (2008, p. 49) "A história permite a construção de um significado compartilhado entre os envolvidos no projeto, alinhando pensamentos e ações numa área cujo produto e matéria-prima não podem ser vistos, tampouco tocados".

Monteiro e Valentim (2008) abordam as necessidades informacionais e aprendizagem no ciclo de vida de um projeto destacando a importância da gestão de projetos em unidades de informação. Nesse estudo, os autores ressaltam a elaboração e implementação de projetos inovadores e descrevem o ciclo de vida de um projeto. Por meio de um estudo teórico apresentam conceitos de gestão de projetos alinhados aos fluxos informacionais mostrando a relevância da aplicação do ciclo de vida de projetos para tomada de decisão dos gestores visto que a informação atualmente permeia todas as organizações. Conforme Monteiro e Valentim (2008, p. 58) "Os gestores de projetos precisam ter muita habilidade na busca, seleção e uso das informações, para que possam tomar decisões adequadas, uma vez que, geralmente um projeto traz consigo um acentuado componente de incerteza".

Percebe-se que as necessidades de informação em cada fase do ciclo de vida do projeto não são uniformes e tem necessidades próprias. Conforme o projeto se amplia a necessidade de monitorar as informações também aumentam. Corroborando com Monteiro e Valentim (2008) é importante enfatizar que a Ciência da Informação pode contribuir bastante com a gestão de projetos nas organizações para que os mesmos alcancem êxito desde a fase de planejamento, implementação e finalização do projeto. 
As ideias apresentadas por Monteiro e Falsarella (2007), Monteiro e Valentim (2008), Brusamolin e Moresi (2008) fortalecem a importância da gestão da informação para o sucesso da gestão de projetos visto que a informação se apresenta como um fator crítico de sucesso nas organizações e por isso precisa ser gerenciada de forma eficiente e eficaz.

Ambas relatam a relevância de estudos mais aprofundados sobre essa temática pela importância que se apresenta no atual contexto informacional e por isso, esse estudo foi desenvolvido visando alinhar as melhores práticas do $P M B O K \otimes$ aplicado à gestão de projetos em unidades de informação para que seja uma importante ferramenta usada na gestão pelos bibliotecários.

\subsection{Melhores práticas para aplicação do PMBOK® na gestão de projetos em unidades de informação}

Como descrito anteriormente o PMBOK® agrupa processos divididos em dez áreas de conhecimento distintas. Em uma unidade de informação, o bibliotecário pode fazer uso dessas boas práticas visto que também trabalha por meio de processos no seu fazer profissional quando planeja atividades e ações para promover a organização, acesso, recuperação, disseminação e mediação da informação. Como visto na revisão de literatura, essas atividades e ações podem ser desenvolvidas por meio de projetos para alcançar maior eficiência e eficácia nos serviços prestados em uma unidade de informação e facilitar a tomada de decisão do bibliotecário, principalmente no que abarca as funções gerenciais no planejamento, controle e avaliação.

\subsubsection{Gerenciamento de integração do projeto}

A primeira área destacada pelo $\mathrm{PMBOK} \circledast$ é o gerenciamento de integração do projeto cujo grupo é responsável pela abertura, encerramento e gestão das demais áreas.

O gerenciamento da integração do projeto inclui os processos e as atividades necessárias para identificar, definir, combinar, unificar e coordenar os vários processos e atividades dos grupos de gerenciamento. No contexto de gerenciamento de projetos, a integração inclui características da unificação, consolidação, articulação e ações integradoras, que são essenciais para o 
término do projeto, para gerenciar com sucesso as expectativas das partes interessadas e atender aos requisitos (PMBOK, 2013).

Em unidades de informação, uma das competências do bibliotecário é alinhar os processos envolvidos no projeto para que o mesmo alcance o objetivo proposto. Por exemplo, no caso de um projeto para criação de um repositório institucional, o bibliotecário vai atuar junto a uma equipe interdisciplinar formada por profissionais da área de gestão, técnicos e da área de tecnologia da informação. Nesse caso, o bibliotecário precisa gerenciar essas pessoas para que consiga captar o potencial delas e integrar os diferentes perfis, formações e experiências.

\subsubsection{Gerenciamento do escopo do projeto}

A segunda área do PMBOK é o gerenciamento do escopo do projeto, que corresponde a definição de todo o trabalho a ser feito pelo projeto nada a mais e nada a menos do que foi previamente definido, ou seja, o corpus do projeto.

O gerenciamento do escopo do projeto inclui os passos necessários para assegurar que o projeto inclua todo o trabalho necessário, e apenas o necessário, para terminá-lo com sucesso. Os passos para gerenciar o escopo, assim como as ferramentas e técnicas de suporte, variam de acordo com a área de aplicação e normalmente são definidos como parte do ciclo de vida do projeto. Os processos de gerenciamento de escopo precisam estar bem integrados aos das outras áreas do conhecimento para que o trabalho resulte na entrega do escopo do produto especificado (PMBOK, 2013).

É importante que o bibliotecário execute aquilo que foi proposto no escopo do projeto até para facilitar o monitoramento e acompanhamento durante o processo de execução até a finalização. Um exemplo que pode ser aplicado em unidades de informação é quando o bibliotecário precisa promover a acessibilidade em uma biblioteca. O projeto precisa ser muito bem detalhado em seu escopo qual o tipo de acessibilidade, se será somente no acervo, no espaço físico, em serviços ou mesmo na capacitação de pessoas na equipe para promover $\mathrm{o}$ atendimento a essas pessoas que exigem recursos diferenciados para ter acesso à informação. Quando se fala em acessibilidade, 
é importante que esteja claro no escopo do projeto qual o tipo de acessibilidade, pois ela costuma ser associada apenas a questões físicas e arquitetônicas, mas o termo expressa um conjunto de dimensões diversas, complementares e indispensáveis para que haja um processo de efetiva inclusão como a atitudinal, arquitetônica, comunicacional, instrumental, metodológica e programática.

\subsubsection{Gerenciamento do tempo do projeto}

A terceira área envolve o gerenciamento do tempo do projeto, um fator crítico de sucesso em projetos. É responsável por decompor as entregas em atividades e atribuir um tempo a elas, resultando em um cronograma a ser seguido. O tempo, assim como o custo, compõe uma variável muito importante no sucesso de um projeto.

O gerenciamento de tempo do projeto inclui o necessário para gerenciar o término pontual do projeto. Alguns profissionais experientes fazem distinção entre a informação do cronograma do projeto impressa (cronograma) e os dados e cálculos que o produziram, fazendo referência ao mecanismo de agendamento preenchido com os dados do projeto como o modelo de cronograma. Contudo, na prática, o cronograma e o modelo são chamados de cronograma. Portanto, o guia PMBOK usa o termo cronograma (PMBOK, 2013). O tempo é uma variável muito importante em projetos desenvolvidos em unidades de informação e por isso precisam ser muito bem gerenciados já que muitas vezes os projetos são condicionados às ações a serem executadas oriundas de demandas e necessidades percebidas ou identificadas por meio de estudos de usuários pontuais aplicados em determinados períodos.

\subsubsection{Gerenciamento do custo do projeto}

A quarta área do PMBOK envolve o gerenciamento do custo do projeto que tem implicações da gestão de pessoas, recursos, materiais, equipamentos entre outros fatores que demandam pagamentos financeiros e investimentos. $O$ custo junto ao escopo, tempo e a qualidade são as quatro principais áreas que merecem atenção especial do gestor de um projeto visto que vão levar ao sucesso ou fracasso de um projeto. 
O gerenciamento dos custos do projeto inclui os processos envolvidos em estimativas, orçamentos e controle de custos de modo que o projeto possa ser terminado dentro do orçamento aprovado. Esta área preocupa-se principalmente com os custos dos recursos necessários para completar as atividades do projeto. Este deve considerar também o efeito das decisões de projeto no custo recorrente subsequente ao uso, manutenção e suporte do produto, serviço ou resultado do projeto. O esforço de planejamento de gerenciamento dos custos ocorre nas fases iniciais do planejamento do projeto e fornece a estrutura para cada processo do gerenciamento dos custos para que seu desempenho seja eficiente e coordenado (PMBOK, 2013).

Em unidades de informação, os custos podem ser investidos pela própria organização mantenedora da biblioteca ou pela captação de recursos em editais de órgãos públicos e privados que podem investir financeiramente em projetos de cultura, lazer e educação promovidos por bibliotecários. Existe a necessidade de gerenciar muito bem os custos do projeto, definido, acompanhando e controlando os custos, indiferente da forma como os recursos foram captados, para que não haja desperdícios, que facilite a prestação de contas e posteriormente consiga outros recursos financeiros para projetos futuros. Em unidades de informação, por exemplo, ao criar um projeto para assinatura de um portal para acesso às bases de dados, periódicos e e-books, é necessário o controle financeiro visto que será um recurso empregado para promover o acesso a fontes de informação eletrônicas.

\subsubsection{Gerenciamento da qualidade do projeto}

A quinta área do $\mathrm{PMBOK} \circledast$ envolve o gerenciamento da qualidade do projeto, responsável por especificar o nível de aceitação e garantir que este seja atingido ao longo de todo projeto. A qualidade é fator imprescindível e por isso precisa ser monitorado ao longo do projeto.

O gerenciamento da qualidade do projeto inclui os processos e as atividades da organização executora que determinam as políticas de qualidade, os objetivos e as responsabilidades, de modo que o projeto satisfaça as necessidades para as quais foi empreendido. Implementa o sistema de gerenciamento da qualidade por meio de políticas e procedimentos com 
atividades de melhoria contínua de processos, realizadas durante todo o projeto, conforme apropriado. O gerenciamento da qualidade do projeto engloba o gerenciamento do projeto e seu produto e aplica-se a todos os projetos, independentemente da natureza do produto. As medidas e técnicas de qualidade do produto são específicas do tipo de produto resultante do projeto (PMBOK, 2013).

Citando o mesmo exemplo do projeto para aquisição da assinatura de um portal para acesso às bases de dados, a qualidade em unidades de informação está diretamente relacionada ao fornecedor dessa base de dados, às cláusulas que constam no contrato, ao tipo de convênio estabelecido, aos tipos de fontes que terão acesso nesse portal, a atualização das fontes disponibilizadas no portal, entre outros fatores.

\subsubsection{Gerenciamento dos recursos humanos}

A sexta área relaciona-se ao gerenciamento dos recursos humanos do projeto visto que são as pessoas os fatores humanos essenciais na concepção da ideia, planejamento, implementação, acompanhamento e finalização de um projeto independente do alcance e porte.

Segundo o PMBOK (2013) o gerenciamento dos recursos humanos do projeto inclui os processos que organizam e gerenciam a equipe do projeto. $A$ equipe consiste nas pessoas com papéis e responsabilidades designadas para a conclusão. O tipo e o número de membros da equipe podem mudar com frequência ao longo do projeto. O envolvimento e a participação dos membros da equipe desde o início agregam seus conhecimentos durante o planejamento e fortalece o compromisso com o projeto. A equipe de gerenciamento de projetos é um subconjunto da equipe do projeto e é responsável pelas atividades de gerenciamento e liderança, como iniciação, planejamento, execução, monitoramento, controle e encerramento de várias fases. Esse grupo também pode ser chamado de equipe principal, equipe executiva ou equipe de liderança. Para projetos menores, as responsabilidades de gerenciamento podem ser compartilhadas por toda a equipe ou administradas exclusivamente pelo gerente de projetos.

O gerenciamento das pessoas envolve a identificação, alocação, 
provisão e o crescimento dos indivíduos alocados nos projetos, por isso precisam ser capacitados e acompanhados no decorrer do projeto. Por meio do desenvolvimento das competências (conhecimentos, habilidades e atitudes) é possível que o bibliotecário gestor tenha pessoas capacitadas para fazer o projeto sair do papel e se transformar efetivamente em uma ação de melhoria na prestação de serviço ou criação de um produto na unidade de informação.

Em unidades de informação é comum ter colaboradores no quadro funcional que não tem conhecimento técnico na área e são remanejados para bibliotecas sem ter perfil ou vocação para trabalhar nesses espaços. Por isso, torna-se importante fazer esse acompanhamento e a capacitação quando necessária para qualificar essas pessoas para que o êxito do projeto não seja prejudicado.

\subsubsection{Gerenciamento das comunicações do projeto}

A sétima área está relacionada ao gerenciamento das comunicações do projeto visto que a informação precisa fluir entre as pessoas da equipe de trabalhos e todos os stakeholders (partes interessadas) envolvidos no projeto para que o prazo, custo e qualidade final não sejam prejudicados e nem sofram alterações significativas a ponto de não atingir o objetivo inicial definido no escopo do projeto.

O gerenciamento das comunicações do projeto inclui os processos necessários para assegurar que as informações do projeto sejam geradas, coletadas, distribuídas, armazenadas, recuperadas e organizadas de maneira oportuna e apropriadas. Os gerentes de projeto gastam a maior parte de seu tempo se comunicando com os membros da equipe e outras partes interessadas no projeto - internas (em todos os níveis da organização) ou externas à organização. Comunicação eficaz cria uma ponte entre as diversas partes interessadas envolvidas no projeto, conectando vários ambientes culturais e organizacionais, diferentes níveis de conhecimento e diversas perspectivas e interesses na execução e nos resultados do projeto (PMBOK, 2013).

Essa área é responsável por identificar, criar e controlar as formas e canais de comunicação seja interno ou externo ao projeto. Em unidades de 
informação um ambiente propício que pode auxiliar na comunicação da equipe é o desenvolvimento de uma wiki. Por ser um ambiente colaborativo muito usado na área de educação, a wiki pode ser aplicada também nas organizações para promovera a gestão da informação e efetivar a comunicação na equipe. Por meio da construção social, a wiki permite a troca de ideias ativas pelos colaboradores que podem interagir nesse ambiente escrevendo, discutindo e refletindo sobre seus conhecimentos, percepções, dificuldades, experiências facilitando a aprendizagem organizacional e armazenamento do conhecimento explícito.

\subsubsection{Gerenciamento dos riscos do projeto}

A oitava área compreende o gerenciamento dos riscos do projeto, responsável pela identificação e análise das oportunidades, ameaças que possam incorrer pelo menos um dos objetivos do projeto. E por fim, respostas adequadas a estas.

Para o PMBOK (2013) o gerenciamento dos riscos do projeto inclui planejamento, identificação, análise, planejamento de respostas, monitoramento e controle de riscos de um projeto. Seus objetivos são aumentar a probabilidade e o impacto dos eventos positivos e reduzir a probabilidade e o impacto dos eventos negativos no projeto. $O$ risco do projeto é sempre futuro e é um evento ou uma condição incerta que, se ocorrer, tem efeito em pelo menos um objetivo do projeto.

Os objetivos podem incluir escopo, cronograma, custo e qualidade. Um risco pode ter uma ou mais causas e, se ocorrer, pode ter um ou mais impactos. A causa pode ser um requisito, uma premissa, uma restrição ou uma condição que crie a possibilidade de resultados negativos ou positivos. O risco do projeto tem origem na incerteza existente em todos os projetos. Os riscos conhecidos são aqueles que foram identificados e analisados, possibilitando o planejamento de respostas. Determinados riscos não podem ser gerenciados de forma proativa, o que sugere que a equipe do projeto deveria criar um plano de contingência. $O$ risco que já ocorreu também pode ser considerado um problema.

As unidades de informação estão sujeitas a várias oportunidades e 
ameaças e devem ser devidamente identificadas, qualificadas, quantificadas e dadas as respostas adequadas para se fazer uma gestão efetiva.

\subsubsection{Gerenciamento de aquisições do projeto}

A nona área do PMBOK envolve o gerenciamento de aquisições do projeto, responsável por planejar, executar e gerir as compras, aluguéis, terceirização de recursos sejam bens materiais o mesmo pessoal terceirizado.

Trata-se de uma importante área que precisa obter a devida atenção no caso de projetos desenvolvidos em unidades de informação visto que as aquisições fazem parte dos processos relacionados à compra, permuta ou mesmo doação comum nesse espaço que provê acesso a diferentes fontes e recursos informacionais.

O gerenciamento de aquisições do projeto inclui os processos necessários para comprar ou adquirir produtos, serviços ou resultados externos à equipe do projeto. O gerenciamento das aquisições do projeto abrange os processos de gerenciamento de contratos e controle de mudanças que são necessários para desenvolver e administrar contratos ou pedidos de compra emitidos por membros autorizados da equipe do projeto. É de responsabilidade da equipe de gerenciamento do projeto assegurar que todas as aquisições atendam às necessidades específicas do projeto e, ao mesmo tempo, cumpram as políticas de aquisição da organização. A equipe de gerenciamento do projeto pode buscar desde o início o apoio de especialistas em contratos, compras, aspectos jurídicos e disciplinas técnicas (PMBOK, 2013).

\subsubsection{Gerenciamento das partes interessadas no projeto}

Por fim, a décima área está relacionada ao gerenciamento das partes interessadas no projeto, foi a área recente inclusa pelo PMI na quinta edição do PMBOK® lançada em fevereiro de 2013. É responsável por identificar, analisar e gerenciar a influências, sejam positivas ou negativas, destes em pelo menos um dos objetivos do projeto e está estruturada em quatro processos: "Identificar as partes interessadas", "Desenvolver o plano de gerenciamento das partes interessadas", "Gerenciar o envolvimento das partes interessadas" e "Monitorar e controlar o envolvimento das partes interessadas". 
As partes interessadas em unidades de informação envolvem não somente os clientes que serão as principais beneficiadas dos projetos desenvolvidos por bibliotecários, mas também a instituição mantenedora, os fornecedores das bases de dados, acervos, equipamentos, mobiliários e as instituições que proveram os recursos financeiros para que projeto fosse implementado e tem grande importância na gestão de um projeto conforme imagem 5.

Figura 5 - Áreas de conhecimento do PMBOK alinhados aos projetos

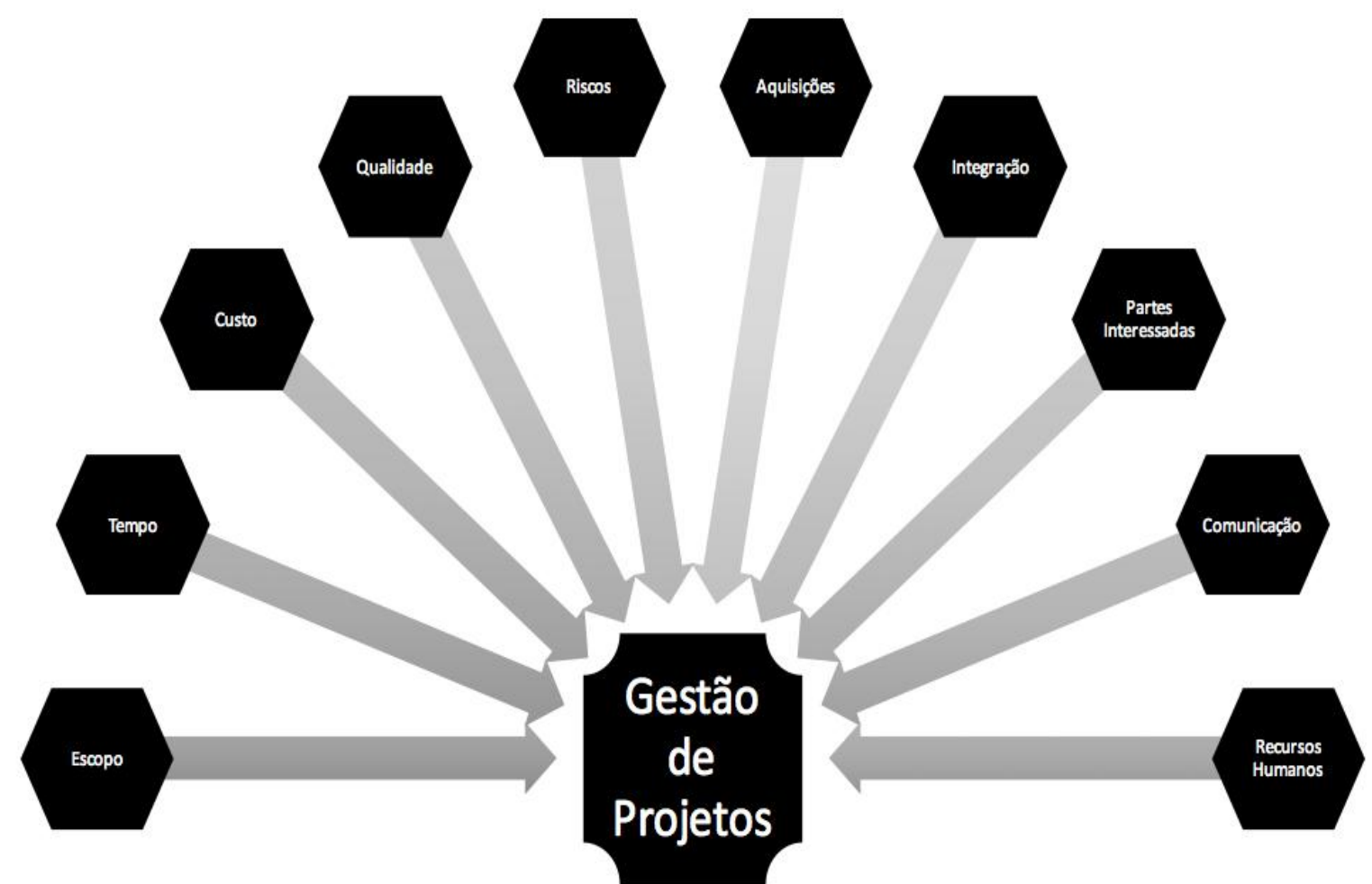

Fonte: Autores com base em PMBOK (2013).

Como se percebe as dez áreas do conhecimento de boas práticas do PMBOK® para gerenciamento de projetos estão inter-relacionadas e podem ser aplicadas em unidades de informação conforme descritas nesse artigo e exemplificadas em projetos comuns criados por bibliotecários. Cada área é composta por processos que agrupam a iniciação (02 processos), o planejamento (24 processos), a execução (08 processos), o monitoramento e 
controle (11 processos) e por último o encerramento (02 processos) que podem ser adaptados para serem usados em unidades de informação pelos bibliotecários no gerenciamento de projetos.

É importante que os bibliotecários busquem capacitações e certificações para estarem aptos para aplicação das boas práticas de gerenciamento de projetos em suas instituições. Uma das formas de obter essa credencial é por meio da certificação Project Management Professional (PMP) emitida pelo PMI aos profissionais que satisfazem a todas as condições do programa de certificação reconhecida mundialmente. De acordo com Bomfin, Nunes e Hastenreiter (2012, p. 70). “A certificação PMP é vista por muitas empresas como uma evolução da carreira profissional e cada vez mais são exigidas para o mercado de trabalho. A partir dessa certificação o profissional aperfeiçoa o conhecimento em gerenciamento de projetos com base no guia PMBOK"

Dependendo da área e do tempo de experiência do bibliotecário que desempenhar a função de gestor de projetos, pode incorrer maiores dificuldades como na área de gerenciamento da qualidade, por exemplo, cujo tempo de experiência prática interfere no projeto assim como o gerenciamento de recursos humanos que necessita uma maior expertise comportamental por parte do gestor. Já as áreas de aquisição e comunicação independem do tempo de experiência e são inerentes a todos os profissionais e importantes ao longo do desenvolvimento do projeto.

\section{CONSIDERAÇÕES FINAIS}

Percebe-se que existem três dimensões no gerenciamento de projetos que envolvem: o ciclo de vida; o grupo de processos e; as áreas de conhecimento que compõem as boas práticas do PMBOK®. Sendo que o ciclo de vida do projeto abrange os requisitos necessários até a operação do projeto. O grupo de processos inclui iniciação, planejamento, execução, monitoramento e encerramento do projeto. Por fim, as áreas de conhecimento são divididas em dez conforme descritas nesse artigo onde cada uma das áreas contém um conjunto de processos que acontece interativamente durante as fases que compõem o ciclo de vida da gestão do projeto. 
Todas as áreas são aplicáveis em projetos desenvolvidos em unidades de informação e cabe ao bibliotecário, que fará a gestão desses projetos, promover a execução, acompanhamento e finalização desses processos para que o PMBOK® seja uma importante fonte para desenvolvimento de projetos por bibliotecários.

Além do $\mathrm{PMBOK} \circledast$, outros esforços podem ser realizados para o desenvolvimento de padrões internacionais e métodos em gerenciamento de projetos como o PRINCE2 ${ }^{\circledR}$ (Project in a Controlled Environment) e o IPMA $®$ (International Project Management Association) que não foram objetos de estudo nesse trabalho, mas que merecem atenção para futuras pesquisas pois se apresentam como oportunidades para vantagens competitivas para as organizações em geral.

As unidades de informação têm como missão promover o acesso as fontes de informação e por isso é importante que sejam adotadas as boas práticas do $\mathrm{PMBOK} \circledast$ pois aceleram o lançamento de produtos e serviços, reduzem custos, melhoram os controles de qualidade e otimizam recursos e esforços.

As unidades de informação estão cada vez mais sendo vistas como organizações prestadoras de serviços cujo principal insumo é a informação que agrega valor às instituições e formação do capital intelectual. Dessa forma, é preciso que haja a preocupação de planejamento e gestão de projetos para atendimento das necessidades informacionais dos clientes que buscam os serviços oferecidos pelas unidades de informação para atendimento dessa demanda.

Os bibliotecários precisam enxergar os projetos como meios de atingir os objetivos e sucesso nas organizações e adotar ferramentas de gerenciamento de projeto que estão baseadas em metodologias de trabalhos como essa do PMBOK® relatado nesse trabalho.

\section{REFERÊNCIAS}

ALMEIDA, Maria Christina. Planejamento de bibliotecas e serviços de informação. 2.ed. Brasília: Briquet de Lemos, 2005. 
BOMFIN, David Ferreira; NUNES, Paula Cristine de Ávila; HASTENREITER, Flávio. Gerenciamento de projetos segundo o Guia PMBOK: desafios para os gestores. Revista de Gestão e Projetos - GeP, São Paulo, v. 3, n. 3, p 58-87, set./dez. 2012.

BRUSAMOLIN, Valério; MORESI, Eduardo. Narrativas de histórias: um estudo preliminar na gestão de projetos de tecnologia da informação. Ciência da Informação, Brasília, v. 37, n. 1, jan./abr. 2008.

GIL, Antônio Carlos. Como elaborar projetos de pesquisa. São Paulo: Atlas, 2010.

MARTINS, Gilberto de Andrade; THEÓPHILO, Carlos Renato. Metodologia da investigação científica para ciências sociais aplicadas. 2. ed. São Paulo, SP: Atlas, 2009.

MAXIMINIANO, Antonio. Administração de projetos: como transformar ideias em resultados. São Paulo: Atlas, 2002.

MONTEIRO, Nabor Alves; FALSARELLA, Orandi Mina. Um modelo de gestão da informação para aprendizagem organizacional em projetos empresariais. Perspectivas em Ciência da Informação, v. 12, n. 2, 2007.

MONTEIRO, Nabor Alves; VALENTIM, Marta Lígia Pomim. Necessidades informacionais e aprendizagem no ciclo de vida de um projeto. Revista Digital de Biblioteconomia e Ciência da Informação, Campinas, v.5, n. 2, p. 53-66, jan/jun. 2008.

\title{
PROJECT MANAGEMENT INSTITUTE. Um Guia do Conhecimento em Gerenciamento de Projetos: Guia PMBOK®. 5. ed.[S.I.]: PMI, 2013.
}

VARGAS, Ricardo. Gerenciamento de projetos: estabelecendo diferenciais competitivos. Rio de Janeiro: Brasport, 2005.

Title

PMBOK@ Application in project management in information units

\begin{abstract}
:
Introduction: The units of information are increasingly being seen as providing services organizations whose main input is the information that adds value to the company and the intellectual capital. Indicating a need for planning to meet the informational needs of its customers. Objective: The aim of this study is to recognize the project management as an alternative to improve from planning and implementation through solutions that meet these needs. Methodology: Was conduced a bibliographic research that pursuit to enhance the use of best practices in project management for helping, and supporting the management of information units. Results: As results, it is pointed out that all ten areas of PMBOK® are applicable to units of information and it is up to the librarian, promote the implementation, monitoring
\end{abstract}


and completion of these processes. Conclusions: Information units is to promote access to information sources and so it is important that best practices are adopted the PMBOK $®$ as accelerate the launch of products and services, reduce costs, improve quality controls and optimize resources and efforts.

Keywords: Project Management. PMBOK. Information Unities. Library Science. Libraries.

\section{Titulo}

A aplicação do PMBOK® na gestión de proyectos em unidades de informação

\section{Resumen}

Introducción: Las unidades de información son cada vez más vistas como organizaciones prestadoras de servicio, cuyo elemento principal es la información que agrega valor y la formación del capital intelectual. Resaltando la necesidad de planeación para la atención de las necesidades de información que tienen sus clientes. Objetivo: El objetivo de este estudio es reconocer la gestión de proyectos como una alternativa para la mejora de la planificación e implementación por medio de soluciones que atiendan esas necesidades. Metodología: Se realizó una investigación basada en un estudio bibliográfico exploratorio que buscado reforzar el uso de las mejores prácticas de gestión de proyecto para ayudar y soportar la gestión de las unidades de información. Resultados: Entre los resultados obtenidos, se apuntan que las diez áreas de $\mathrm{PMBOK} 囚$ son aplicables en unidades de información y que le corresponde al bibliotecario promover la implementación, el seguimiento y la conclusión de esos procesos. Conclusiones: Las unidades de información tienen como misión promover el acceso a las fuentes de información y por eso es importante que sean adoptadas las mejores prácticas de PMBOK® pues estas aceleran la introducción al mercado de productos y servicios, reducen costos, mejoran los controles de calidad y optimizan los recursos y esfuerzos.

Palabras clave: Gestión de Proyectos. PMBOK. Unidades de Información. Biblioteconomía. Bibliotecas.

Recebido: 12.02 .2016

Aceito: 25.03.2017 